\title{
Analysis and generalization of competitive activity results of handball clubs in the game development aspect
}

Solovey O. M. ${ }^{1 \mathrm{ABCDE}}$, Mitova O.O. ${ }^{1 \mathrm{BCDE}}$, Solovey D.O. ${ }^{1 \mathrm{BCDE}}$, Boguslavskyi V.V. ${ }^{2 \mathrm{BCDE}}$, Ivchenko O.M. ${ }^{2 \mathrm{BCDE}}$

${ }^{1}$ Prydniprovsk State Academy of Physical Culture and Sports, Ukraine

${ }^{2}$ Dnipropetrovsk State University of Internal Affairs, Ukraine

Authors' Contribution:

A - Study design; B - Data collection; C - Statistical analysis; D - Manuscript Preparation; E-Funds Collection.

\section{Abstract}

Purpose:

Material:

Results:

Conclusions:

Keywords: an analysis of the competitive activity of men's club handball teams in the final tournament of the European Champions and Champions League Cup gives you the opportunity to determine the rating of the teams on the continent and the development tendencies of the game.

the best men's handball clubs from 52 national federations in Europe which competed in the qualifying tournament and the group stages of the draw and were the winners and prize winners of the European Champions and Champions League Cup of 1956/1957-2017/2018. A systematic review of the available qualitative literature was conducted according to Preferred Reporting Items for Systematic reviews. The "Web of Science", "Physical Education Index (ProQuest)", "Google Scholar" and "Scientific Periodicals Ukraine" databases were used in order to ensure, from an early stage, the scientific quality of the revised studies. The research was conducted based on 'any field' (e.g. title, abstract, text) and no restrictions were made regarding the language of publication. The terms used in the research were "teams scoring performance", "elite handball", "game location", "players exclusions", "home advantage", "quality", "opposition", and "indicators". The quality of the articles was assessed by a set of criteria developed by members of the Evidence for Policy and Practice Information and other specialists. The initial search found 132 journal articles; for a final list of 52 publications.

The article covers the organizational aspects of the competitive activity of men's handball clubs in Europe at the European Champions and Champions League tournaments from 1956 to 2018. The given analysis of the highest achievements of the leading handball clubs which are not only winners and prize winners, but also the countries that they represented. The winners and prize winners are marked both between teams of different countries and teams of one country.

Achievements and rankings of the leading handball clubs in the international arena are the main components of preparing them for official competitions: new approaches to planning the preparation of players and teams for higher sports achievements and maximum realization of individual opportunities; the integration of the individual readiness of highly skilled handball players into leading handball clubs; to the important aspects of the new rules of the game, which are developed in the theory and implemented in practice; the main tendencies in the international and European handball that systematically develop and apply to a core of players as well as the next reserve.

handball, cup tournaments, competitive activity, team-winners, handball leaders.

\section{Introduction}

The modern handball is characterized by a high degree of competition of leading world teams both at the level of national teams and club teams. This situation contributes to the increase in the level of athletic skill of individual players and teams in general [1-4]. Every year handball is becoming more and more popular. The Olympic Games, World and European Championships, European club cups and other types of competitions are regularly held [5-8].

The current tendencies in handball development make it possible for specialists to state that not just the best team but the team that is better prepared for specific official games usually wins. It's not about the tactics of a game that coaches play in teams, but in philosophy, in the fantastic atmosphere they create in teams [9-14]. Each coach deserves recognition, they perform incredible work in teams and this is the reflection of their character, their fighting spirit. Over the years, scientists and coaches have been trying to anticipate these trends and factors that o Solovey O. M., Mitova O.O., Solovey D.O., Boguslavskyi V.V., Ivchenko O.M., 2020 doi:10.15561/18189172.2020.0106 influence the effectiveness of competitive activity [15-18]. Taking into account the technical and tactical indicators of the best handball players in competitions of various rank, it becomes clear that the issue of management of training and competition processes to a large extent determines the effectiveness of technical and tactical activity and the ability to achieve a high sporting result [19-22]. It is believed among many scholars [23-26] that sporting results are an integral indicator of athletes' preparedness. In our opinion, it also has a connection with the system of training. Male sportsmen played the 58-th finals and the 24th after the European Champions Cup was renamed into the Champions League [6, 27-30]. However, the most prestigious club tournament under the auspices of the European Handball Federation (EHF) is worth telling more about it. The turning point in the development of the tournament is the 1993/1994 season, when the Champions League of the European Handball Federation was created instead of the European Champions Cup. Now the group stage is added to the stages of the playoffs. The number of its participating teams increased to 28 teams over the time 
$[6,13,28,31,32]$.

Research hypothesis. The systematization of the results of the competitive activity of men's handball clubs will provide new knowledge about the distribution of handball leaders, the place of various handball schools in the European ranking, which will help to find new approaches to planning the preparation of players and teams to higher sports achievements, forecasting the results of competitions, the selection of players in the teams, etc.

The aim of the research is to analyze the involvement of male handball club teams in the final tournament of the European Champions and Champions League Cup and to determine the tendencies of the game.

\section{Materials \& methods}

Data sources.

The best men's handball clubs from 52 national federations of European countries, who passed the qualifying tournament for the group stage of the European Champion and Champions League Championship 1956/1957-2017/2018, and won the prestigious trophy, were analyzed.

\section{Search procedures and criteria}

A systematic review of the available qualitative literature was conducted according to Preferred Reporting Items for Systematic reviews. The "Web of Science", "Physical Education Index (ProQuest)", "Google Scholar" and "Scientific Periodicals Ukraine" [33] databases were used in order to ensure, from an early stage, the scientific quality of the revised studies. The research was conducted based on 'any field' (e.g. title, abstract, text) and no restrictions were made regarding the language of publication. The terms used in the research were "teams scoring performance", "elite handball", "game location", "players exclusions", "home advantage", "quality", "opposition", and "indicators". The quality of the articles was assessed by a set of criteria developed by members of the Evidence for Policy and Practice Information [34] and other specialists [35]. The initial search found 132 journal articles; for a final list of 52 publications. Data search was carried out using protocols that are on the Internet at the European Handball Federation (EHF) website, the participation of handball clubs in the tournaments, their victories and defeats. Pedagogical analysis of the participation of handball clubs in Europe was conducted on the basis of official data of the final tournaments of the European Champions Cup (1956 - 1992/1993) and the Champions League (1993/94 - 2017/18) of the EHF, presented winners and finalists both among teams from different countries and one country.

Research methods. Theoretical analysis and generalization of scientific-methodical literature and technical protocols in the Internet; method of system analysis; chronological method. The study of scientific and methodological literature allowed to formulate the problem, to determine the degree of relevance of issues that were solved during the research, to substantiate theoretically the purpose and objectives of the work.
Statistical analysis. Descriptive statistics were used for the statistical analysis of the survey. The mathematical statistics were carried out by the method of calculating the quantitative indicators of the participation of handball clubs in the Cup of European Champions and League of Europe as well as between clubs of different countries.

\section{Results}

To improve the effectiveness of handball management internationally, all national federations are geographically united into five continental federations. The new rise in the development of handball began with the creation of the new European Handball Federation - EHF in Berlin (Germany) in November 1991 and it included in its membership 29 national European associations that were members of the International Handball Federation (IHF). Nowadays the European Federation has 52 national federations, of which 3 are members of the EHF with the rights of associate members, namely England, Kosovo and Scotland. The European Handball Federation represents the International Handball Federation in European countries $[6,28,29,36]$. The European Handball Club Tournaments which were previously held under the auspices of the International Handball Federation, have since moved under the jurisdiction of the EHF since 1993. So, under the auspices of the EGF are the following: official European championships representing the Olympic sport and club competitions representing a professional (commercial) sport. It should be noted that holding cup tournaments is characteristic only for the continental level $[6,28,31,37]$.

As part of its activity the European Handball Federation is responsible for conducting European tournaments for men's and women's club teams (Champions League EHF, EHF Cup Winners' Cup, European Handball Federation Cup (since 2012, men's tournaments of the Cup Winners' Cup and the EHF Cup are combined into one tournament EHF Cup), EHF Challenge Cup) annually. The Champions League is the largest competition for handball clubs in Europe. The tournament, which until the 1993/994 season was called the European Championship Cup, is held annually by the International Handball Federation (IHF) since 1956 for men's teams and since 1961 for women's teams. Currently, it is held under the auspices of the European Handball Federation (EHF). Between 1956 and 2019, 59 European tournaments were held, including 33 European Champions Cup and 26 Champions League tournaments, in which male handball clubs of 52 national federations participated in various stages of the draw. In the European Champions Cup and Champions League there are teams from 27 countries with the highest club rating. The tournament takes place in several stages (preliminary round, qualification, group stage, play-offs, final four). In the finals of the prestigious trophy of Europe, 52 handball clubs from 19 national federations participated and only 33 clubs from 15 countries celebrated victories and 39 clubs from 17 European countries were defeated in the finals. The first draw of the Cup involved 12 teams representing the great cities of Europe. The finals with 
the participation of Czechoslovak handball players from Prague and the Swedish champions from Orebro took place on March 9, 1957 in Paris, and brought the victory to the Prague team - 21:13, which became the first winner of the tournament.

From the next draw in the tournament only club teams - champions of their countries began to participate. The finals from the $1956 / 57$ seasons to $1977 / 78$ took place in one game, from the seasons $1978 / 79$ to $2008 / 09$ - in two games, and from the $2009 / 10$ season - again in one game. One final of the 1983-84 season determined the winner between teams of Dukla (Czechoslovakia) and Metalloplastika (Yugoslavia) with a series of 7-meter throws, as each of the teams at their site won the same score - 21:17, and on the 7-meter throws Czechoslovak handball players won.

An analysis of the achievements of leading winning countries shows that German clubs are historically dominated in men's tournaments. So, 13 clubs won 19 victories and lost 12 in the finals: according to the Federal Republic of Germany - 4 clubs, 8 wins and 3 defeats, GDR - 5-3-2, from the 1992/93 season Germany - 5-6-7). From the $1989 / 90$ season, the championship in the ranking was headed by Spanish clubs (6 clubs won 15 victories and defeated in 12 finals, with only one lost final before this Atlético (Madrid) season 1984/85) (tab. 1).

It is worth noting that one of the most interesting cases of handball clubs in these countries is that most of the finals of the prestigious tournament they played between clubs of one country or between clubs of these countries. The competitors for German and Spanish clubs were and still are handball clubs of the USSR ( 3 clubs won 5 victories and 3 finals lost), Yugoslavia (respectively 6 4 and 7), Czechoslovakia (2 - 3 - 2), Romania (2-3-3), France (3 - 2 - 2), Croatia (1 - 2 - 4), Macedonia (1 - 2-0). One champion's trophy was won by Slovenian clubs (1 1-0), Hungary (2-1-4), Sweden (1 - 1-0), Poland (3-1-3). Handball clubs in 4 other European countries played in the Champions Cup finals, Denmark (2 clubs were finalists), Iceland, Portugal and Switzerland lost in one final. 13 German handball clubs won in 19 finals and defeated in 12 finals, of which 4 were purely German (1970, 1979, 2007, 2014), 6 finals played between German and Spanish clubs (which won three club victories of each of the countries), 4 - Yugoslav clubs (3 victories and 1 defeat), 3 - clubs of the USSR (2-1), 2 - Hungarian clubs (2-0). There should be noted the victories of German clubs over the clubs of Denmark (1960), Czechoslovakia (1967), Romania (1971), Poland (1978) and Iceland (1980), as well as the defeat of the clubs of Sweden (1959), Croatia (1993) and Slovenia (2004). Six Spanish handball clubs in the 15 finals were stronger than their opponents, 12 finals were lost. Spanish clubs were played in 22 finals, of which 5 were purely Spanish (1996, 2001, 2005, 2006, 2011). The Spanish clubs were stronger than the clubs of six European countries, primarily the clubs of Yugoslavia (1991), Portugal (1994), Croatia (1995, 1997-1999), Germany (2000, 2008, 2009), Hungary (2015) and lost to the clubs of Yugoslavia (1985), USSR (1990), Croatia (1992), France (2003) and Germany (2010, 2012, 2013).

To a large extent, the European Champions Cup (Champions League) can safely be called the Spanish "Barcelona" tournament; at least Spanish clubs are always considered favorites. Spanish "Barcelona" is the undisputed leader in the European handball to gain honorary trophies. Starting from the 1990/91 season, "Barcelona" handball players won 9 Champions Cup and Champions League titles (1991, 1996-2000, 2005, 2011,2015 ), moreover, from the $1995 / 1996$ season to 1999/2000 for five consecutive seasons the cup remained in the hands of Spanish athletes. In four finals handball players of "Barcelona" suffered defeats from their opponents: SKA (USSR) - 1990; Portland San Antonio (Spain) - 2001; Kiel (Germany) - 2010; Hamburg (Germany) - 2013. "Barcelona" handball players always behave as hosts on the court, dominating from the first until the last minute. Even if the matches were equal, psychological advantage was entirely on the side of the Catalans. German club "Gummersbach" took part in 6 finals and won 5 Champions Cups (1967, 1970, 1971, 1974, 1983), handball players of the German club "Kiel" won 3 Champions League Cups in 7 finals (2007, 2010, 2012), the Spanish "Ciudad Real" - 3 in 5 finals (2006, 2008-2009), the German "Magdeburg" - 3 in 4 finals (1978, 1981, 2002), Croatian «Zagreb» - 2 in 6 finals (1992-1993).

$100 \%$ of the participation in the prestigious handball tournament competitions belongs to the handball players of the SCA (Minsk, USSR) - 1987, 1989, 1990, and Montpellier (France) - 2003, 2018, which won all the matches against their opponents. The analysis of the final matches between clubs from different countries shows that German clubs met six times in the finals with the clubs of Spain and shared all the victories equally - won 3 times in each country (German clubs "Kiel" 2010, 2012, "Hamburg" - 2013 and Spanish "Barcelona" - 2000, "Ciudad Real" - 2008-2009). Clubs of Spain and Croatia have met five times in Champions Cup and Champions League finals. In 4 finals, the Spanish handball players (Zagreb defeated Bidasoa 1995 and Barcelona, 1997-1999) were stronger, and in 1 final, the Croatian Zagreb won the Cantabrian club (1992). In the three finals handball players from the clubs of Germany and the Soviet Union played, the German clubs that won 2 European Championship Cups $(1974,1983)$ and 1 lost (1988) were stronger.

It should be noted that the handball clubs of Romania (1977) and the Soviet Union (1989), as well as the clubs of Czechoslovakia (1963) and Romania (1968), played twice in the finals with each other and won one victory. Historical events, namely the results of the participation of the best handball clubs of different years in the competitions of the European Cup, contributed to the scientific methodical literature, enriched the knowledge of specialists in the field of physical culture and sports, fans of handball. 


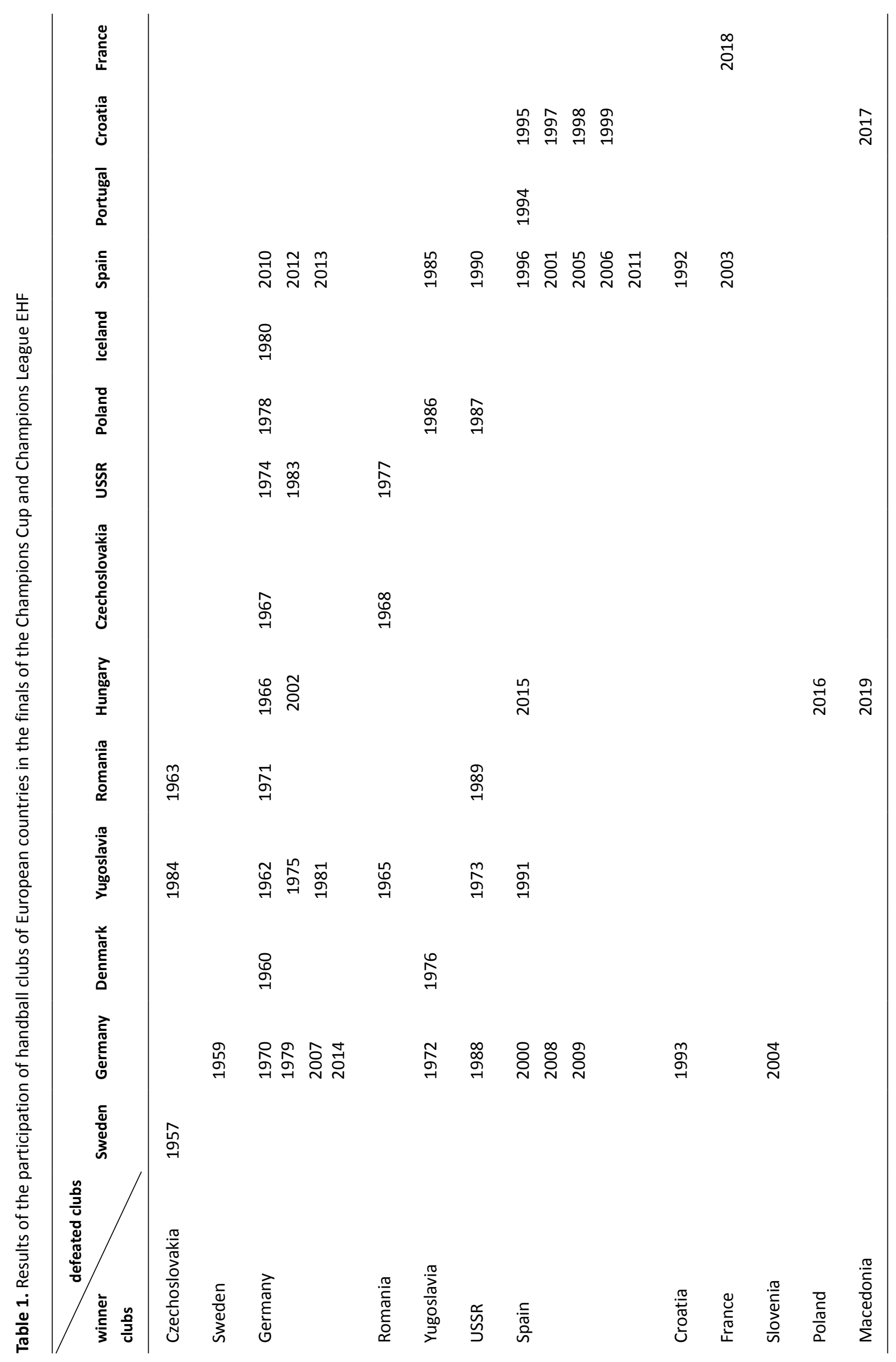




\section{Discussion.}

Competitive process is constantly progressing, the number of competitions among handball clubs and at the level of national teams of these countries is growing every year, the sports qualification of participants of such competitions is constantly increasing. The game of handball teams, both foreign clubs and domestic ones, is built not only around experienced stars. Any club, if it wants to be entrenched in the elite firmly and for a long time, should focus on the preparation of its own reserve [38-41]. The foregoing determines the peculiarities of conducting a training process, the sole purpose of which is to achieve a positive result in the competitions. The focus and content of the training of handball players in clubs is as follows: athletic training of players, based on the ability to perform actions of speed-force character, that is, martial arts; group interactions that determine the minimum of improvisation and acceptance of mostly simple decisions; and actually a team game in general. Problems of increasing the athletic skill of handball players are significant in the current conditions of sports development of higher achievements. Competition and social significance of games, victories and achievements of leading teams in official prestigious tournaments are increasing

Over the past 20 years, in the competition between the clubs of the five largest European handball leagues (the Bundesliga - Germany, the Premier League - Spain, the First Division of the National Handball League - France, the Superleague - Macedonia, the Polish Handball Cup Poland) there has been evident a sharp distinction in the development of club handball [5, 39, 40, 42]. Successful clubs get bonuses that are getting bigger. At the same time, several leading handball clubs, thanks to big profits, increase the gap from other clubs of European countries, namely Vive Kielce (Poland), PSG, Nantes (France), Barcelona (Spain), Flensburg-Kandevitt, Kiel (Germany), Veszprém, Szeged (Hungary), Vardar (Macedonia). This allows them to strengthen competitive positions in sport, increasing the likelihood of new success. The general trend in the development of an international club handball is the movement of handball players to handball clubs where there are strong national championships for the purpose of participating in official international tournaments, gaining competitive experience of the corresponding level, as well as the desire to improve living conditions. They are the leaders of their national teams and successfully perform their duties in club level competitions.

In addition, the presence of a contract with professional clubs of European countries with a high level of handball development (Spain, Germany, France) is important for a successful professional career of highly skilled handball players. Highly skilled handball players are moving to handball clubs from other countries into strong clubs because their clubs at home have a shortage of investment in sport, planning and infrastructure. And as long as it continues, the leadership must accompany the athletes as best as possible, listening to their needs and working for their development.
As Mats Olsson, a well-known specialist in the training of goalkeepers from Norway and Sweden, says that today the game of the goalkeepers of the leading handball clubs has a major role. He introduces a new fourstage method of training goalkeepers. The most important module of his method is the training of the ability of the goalkeepers to "read" all the relevant gaming situations $[5,28,40,43]$. In the German Bundesliga, in recent years, Michael Bigler has developed a method of "training force pressure" - an innovative approach to defence training to better meet the current complex defensive requirements of competitive handball games, including training with protective pressure and training with attacking pressure [28, 31, 44, 45]. Allan Quintallet, Coach for Physical Training, has made a significant contribution to the achievement of handball players in France. Based on an analysis of the current sports requirements of competing handball activity, he uses the training of explosive gaming activities that are often encountered in the game [27, 31, $39,46]$. An in-depth analysis of the final matches of the Champions League Men's Cup Championship shows how the winning teams tactfully implement the improved option of replacing the goalkeeper with an extra field player.

The game continues with fast breaks against the rearrangement of protection, which is an important strategic element in the modern handball. Specialists in foreign handball target their players to improve the tactical principles and strategy of the offensive game against unorganized protection, to adhere to special technical requirements for fast play, such as different variants of knowing and handing over the ball with one hand in all game situations [6, 47-49]. The throws of the ball into the goal are the culmination of the attacking action of the handball players, so their training is crucial. It should be noted that the attackers of the leading European clubs not only performed throws on the force, but also constantly change the direction of throws, throws from the closed positions, throws in close contact with the defender, change the position of the body while performing throws in the jump. In today's handball, successful bouts both in defence and in the attack are key to winning the game. As handball experts point out, tactfully-prepared players perform a developed action plan for the game in order to be able to win their matches. In addition, in recent years, more specific requirements for each gaming position are developed, and separate tactical attack actions differ from each other, especially for players in the first and second lines of attack [50-52].

\section{Acknowledgements.}

The research was carried out in accordance with the thematic plan of scientific researches of the Prydniprovsk State Academy of Physical Culture and Sports for 20162020 on the theme "Theoretical and Methodical Basics of Planning and Control in Sport Games in the Process of Long-term Improvement", the state registration number $0116 \mathrm{U} 003012$. 


\section{Conclusions.}

In the leading handball countries in Europe, there were and still are the conditions under which handball has been actively developed. Today, the leaders of the world's male handball are the clubs of Germany, Spain, France, Hungary, Poland, Macedonia.

The analysis of scientific material makes it possible to emphasize that the main components of the preparation of the leading handball clubs for official competitions are new approaches to the preparation of players and teams for higher achievements in sport and the maximum realization of individual capabilities, the integration of the individual readiness of highly qualified handball players from the main national teams to the leading handball clubs.

Qualified players from leading European handball clubs are more integrated into important aspects of the new rules of the game, which are developed in theory and implemented in practice (replacing goalkeeper with additional field player, passive game, fights in the free throwing zone, non-prejudiced attitude of judges to performing three steps).

The main tendencies in the international and European handball are systematically developing and spreading for juniors as well as for higher levels of training, first of all, it is a quick game at all stages of preparation (systematic training of players' ability to act quickly, using tempo changes in individual and team actions in combination, tactically significant movements of attackers to open space).

Prospects for further research include the study of the interconnection of the results of the competitive activity of club tournaments with the results of the World and European Championships of leading national teams.

\section{Conflict of interests}

The authors declare that there is no conflict of interests.

\section{References}

1. Doroshenko EYu. Management of technical and tactical activities in team sports games. Zaporozhye: LLC "LIPS" LTD; 2013. (in Ukrainian)

2. Sushko R, Doroshenko E. Globalization in the current world of sport and other sports. Sports visitor Pridniprov ya. 2016; 2: 140-146. (in Ukrainian)

3. Acsinte E, Alexsandru A. The physical condition of highly qualified handball players. European Handball Journal. 2007;1:2-12.

4. Ferrari MR, Sarmento H, Vaz V. Match Analysis in Handball: A Systematic Review. Montenegrin Journal of Sports Science and Medicine. 2019;8(2):63-76. https://doi.org/10.26773/mjssm.190909

5. Rogulj N, Vuleta D, Milanović D, Cavala M, Foretić N. The effi- ciency of elements of collective attack tactics in handball. Kines Slovenica, 2011; 17(1): 5-14.

6. International Federation of Handball [Internet]. 2019 [updated 2019 Jun 15; cited 2019 Sep 5]. Available from: http://www.ihf.info

7. Solovey OM. Handball development in the context of analysis of the goals of the national teams at the championships in Europe and Ukraine. Sports visitor Pridniprov'ya. 2016; 1: 128-131. (in Ukrainian)

8. Cardinale M, Whiteley R, Hosny AA, Popovic N. Activity Profiles and Positional Differences of Handball Players During the World Championships in Qatar 2015. International Journal of Sports Physiology and Performance. 2017;12(7):908-915. https://doi.org/10.1123/ijspp.2016-0314

9. Solovey AM, Solovey DA. Female handball in the history of the development of the Olympic Games. XV International scientific Session on the results of research for 2016, Minsk: BSUFK; 2017. P. 114-117.

10.Kubrachenko AG, Tkachuk VG. Handball: textbook for higher education. Head systems physical educate and sports. Kiev; 2010.

11.Zotova FR, Gerasimova IG, Sadykova SV. Analysis of the development trends of modern sports. Pinsk: Polesskij State University; 2015.

12.Serrien B, Baeyens JP. Systematic Review and Meta-Analysis on Proximal-to-Distal Sequencing in Team Handball: Prospects for Talent Detection? Journal of Human Kinetics. 2018;63(1):9-21. https://doi.org/10.2478/hukin-2018-0002

13.Hansen C, Lopez FS, Whiteley R, Wilhelm A, Popovic $\mathrm{N}$, Ahmed HA, et al. A video-based analysis to classify shoulder injuries during the Handball World Championships 2015. Sportverletzung-Sportschaden. 2019;33(1):30-35. https://doi.org/10.1055/a-0787-6329

14.Vila H, Ferragut C. Throwing speed in team handball: a systematic review. International Journal of Performance Analysis in Sport. 2019;19(5):724-736. https://doi.org/10.1080/24748668.2019.1649344

15.Cyganok VI, Solovey AM. New approaches to the analysis of attacking actions in men's handball of the highest achievements. Sports visitor Pridniprov'ya. 2012; 1: 35-39. (in Ukrainian)

16.Gutiérrez $\mathrm{O}, \quad$ Saavedra $\mathrm{M}, \quad$ Fernández J. Measuring home advantage in Spanish handball. Percept Mot Skills, 2012; 114: 329-38. https://doi.org/10.2466/05.PMS.114.1.329-338

17.Fieseler G, Hermassi S, Hoffmeyer B, Schulze S, Irlenbusch L, Bartels T, et al. Differences in anthropometric characteristics in relation to throwing velocity and competitive level in professional male team handball: a tool for talent profiling. Journal of Sports Medicine and Physical Fitness. 2017;57(78):985-992.

https://doi.org/10.23736/s0022-4707.17.06938-9

18.Fonseca FS, Figueiredo LS, Gantois P, de Lima D, Fortes LS. Relative Age Effect is Modulated by Playing Position but is Not Related to Competitive Success in Elite Under-19 Handball Athletes. Sports. 2019;7(4). https://doi.org/10.3390/sports7040091

19.Barth B, Nowak M. Improvement of the training process of young handball players: goal and independence. Verlag Meer und Meer; 2008.

20.Carbonell V, Fontaina S, Gonzalez A. Study of the technicaltactical actions carried out by elite handball goalkeepers against the pivot 's throws. E-Balonmano Com. 2018;14(1):18.

21.Bjorndal CT, Luteberget LS, Holm S. The Relationship Between Early and Senior Level Participation in International Women's and Men's Handball. Journal of Human Kinetics. 2018;63(1):73-84. https://doi.org/10.2478/hukin-2018-0008

22.Bjorndal CT, Ronglan LT, Andersen SS. Talent development 
as an ecology of games: a case study of Norwegian handball. Sport Education and Society. 2017;22(7):864-877. https://doi.org/10.1080/13573322.2015.1087398

23.Godik MA, Skorodumova AP. Comprehensive control in sports games. Moscow: Soviet sport; 2010. (in Russian)

24.Melnik VO. Improving the attacking tactical actions of handball players at the stage of preparation for the highest achievements. Lviv: Lviv state University Culture; 2015. (in Ukrainian)

25.Jagiello W, Dornowski M, Jagiello M. Perkal's natural indicators method in assessing body composition properties in persons practising combat sports - an analysis research results. Archives of Budo Science of Martial Arts and Extreme Sports. 2018;14:75-80.

26.Maurelli O, Bernard PL, Dubois R,Ahmaidi S, Prioux J.Effects of precompetitive preparation period on the isokinetic muscular characteristics in world class handball PLAYERS. Journal of Strength and Conditioning Research. 2019;33(4):1065-1074. https://doi.org/10.1519/jsc.0000000000002199

27. Sushko R. Features of the current impact of globalization on the development of sports games. Science in Olympic sports. 2018; 4: 39-45. (in Ukrainian) https://doi.org/10.32652/olympic2018.4_4

28.The European Federation of Handball [Internet]. 2019 [updated 2019 Jun 15; cited 2019 Sep 5]. Available from: http://www.evrohandball.com

29.Tabben M, Landreau P, Chamari K, Juin G, Ahmed $\mathrm{H}$, Farooq A, et al. Age, player position and $2 \mathrm{~min}$ suspensions were associated with match injuries during the 2017 Men's Handball World Championship (France). British Journal of Sports Medicine. 2019;53(7):436-445. https://doi.org/10.1136/bjsports-2018-099350

30.Hansen C, Sanz-Lopez F, Whiteley R, Popovic N, Ahmed HA, Cardinale M. Performance analysis of male handball goalkeepers at the World Handball championship 2015. Biology of Sport. 2017;34(4):393-400. https://doi.org/10.5114/biolsport.2017.69828

31.EFH CUP History. [Internet]. 2019 [updated 2019 Jun 15; cited 2019 Sep 5]. Available from: http://europeancup. eurohandball.com/ehfc/en/history

32. Solovey OM. Evaluation of the mental activity of handball on the Olympic Tournament in Rio De Janeiro - 2016. Sports visitor Pridniprov'ya. 2017; 1: 91-94. (in Ukrainian)

33.Vernadsky National Library Electronic Resources. Scientific Periodicals Ukraine. [Internet]. 2019 [updated 2019 Jun 15; cited 2019 Sep 5]. Available from: http://www.nbuv.gov.ua/ node $/ 2116$

34.Harden A. Applying systematic review methods to studies of people'sviews:anexamplefrompublichealthresearch.Journal of Epidemiology \& Community Health, 2004;58:794-800. https://doi.org/10.1136/jech.2003.014829

35.Popay J, Roberts H, Sowden A, Petticrew M, Arai L, Rodgers $\mathrm{M}$, et al. Guidance on the Conduct of Narrative Synthesis in Systematic Reviews. A Product from the ESRC Methods Programme. Swindon: Economic and Social Research Council; 2006.

36.Hatzimanouil D. Goalkeepers' rating, evaluation and classification, according to the number of games, participation time and effectiveness at the Women's European Handball Championship in 2018. International Journal of Performance Analysis in Sport. 2019;19(4):595-607. https://doi.org/10.1080/24748668.2019.1642676

37.Federation of Handball of Ukraine [Internet]. 2019 [updated 2019 Jun 15; cited 2019 Sep 5]. Available from: http://www. handball.net.ua

38.Pavlyuk IS. Organize the basics of developing game sports in
Ukraine (on handball applications). Kiev; 2008.

39. Meletakos P, Bayios I. General trends in European men's handball: a longitudinal study. International Journal of Performance Analysis of Sport. 2010; 10: 221-228. https://doi.org/10.1080/24748668.2010.11868517

40.Rogulj N, Srhoj V, Srhoj L. The contribution of collective attack tactics in differentiating handball score efficiency. Coll Antropol, 2004; 28(2): 739-46.

41.Saavedra JM, Thorgeirsson S, Chang M, Kristjansdottir H, Garcia-Hermoso A. Discriminatory Power of Women's Handball Game-Related Statistics at the Olympic Games (2004-2016).JournalofHumanKinetics. 2018;62(1):221-229. https://oi.org/10.1515/hukin-2017-0172

42.Milanovic D, Vuleta D, Jerak T. Competition performance of elite male and female handball teams: features and differences. Milanovic D, Sporis G, Salaj S, Skegro D, editors. 2017. P. 376-379 p.

43. Sebastia-Amat S, Espina-Agullo JJ, Chinchilla-Mira JJ. Jump height, velocity, flexibility and anthropometric profile of handball goalkeepers in young categories. Retos-Nuevas Tendencias En Educacion Fisica Deporte Y Recreacion. 2017(32):248-251.

44.Daza G, Andres A, Tarrago R. Match Statistics as Predictors of Team's Performance in Elite competitive Handball. Ricyde-Revista Internacional De Ciencias Del Deporte. 2017;13(48):149-161. https://doi.org/10.5232/ricyde2017.04805

45. Costa GDT, Pedrosa GF, de Souza NP, Gemente FRF, Freire $\mathrm{AB}$, Castro HD. Type of game practiced in handball according to the positions of the attackers: analysis of the Women's World Handball Championship 2015. International Journal of Performance Analysis in Sport. 2017;17(3):360-373. https://doi.org/10.1080/24748668.2017.1345197

46.Zapardiel JC, Vila H, Manchado C, Rivilla-Garcia J, Ferragut $\mathrm{C}$, van den Tillaar R. Effect of opposition and effectiveness of throwing from first and second line in male elite handball during competition. Kinesiologia Slovenica. 2019;25(1):3544.

47.Andersson SH, Cardinale M, Whiteley R, Popovic N, Hansen C, Lopez FS, et al. Video analysis of acute injuries and referee decisions during the 24th Men's Handball World Championship 2015 in Qatar. Scandinavian Journal of Medicine \& Science in Sports. 2018;28(7):1837-1846. https://doi.org/10.1111/sms.13090

48.Fasold F, Redlich D. Foul or no Foul? Effects of Permitted Fouls on the Defence Performance in Team Handball. Journal of Human Kinetics. 2018;63(1):53-59. https://doi.org/10.2478/hukin-2018-0006

49.Lopez SS, Perez MAR. Strategies to Optimize Strength and Endurance Concurrent Training in Elite Handball. E-Balonmano Com. 2017;13(1):15-26.

50.Bojic-Cacic L, Vuleta D, Milanovic D. Position-related differences in morphological characteristics of u14 female handball players. Kinesiology. 2018;50(2):235-242. https://doi.org/10.26582/k.50.2.12

51.Saavedra JM, Porgeirsson S, Kristjansdottir H, Chang M, Halldorsson K. Handball game-related statistics in men at Olympic Games (2004-2016): Differences and discriminatory power. Retos-Nuevas Tendencias En Educacion Fisica Deporte Y Recreacion. 2017(32):260-263. https://doi.org/10.1515/hukin-2017-0172

52.Kvorning T, Hansen MRB, Jensen K. Strength and conditioning training by the danish national handball team before an olympic tournament. Journal of Strength and Conditioning Research. 2017;31(7):1759-1765. https://doi.org/10.1519/jsc.0000000000001927 


\section{Information about the authors:}

Solovey O.M.; (Corresponding author); http://orcid/org/0000-0001-8480-2324; 1Soloveyaleksandr@gmail.com; Dean of faculty of physique education, Prydniprovsk State Academy of Physical Culture and Sports; Naberezhna Pobedy str., 10, Dnieper, 49010, Ukraine.

Mitova 0.O.; http://orcid/org/0000-0002-4309-9261; elenamitova@ukr.net; Manager by the Department of Sport Games, Prydniprovsk State Academy of Physical Culture and Sports; Naberezhna Pobedy str., 10, Dnieper, 49010, Ukraine.

Solovey D.O.; http://orcid/org/0000-0001-8105-2061; 1Soloveydmitriy@gmail.com; Department of Sports Games, Prydniprovsk State Academy of Physical Culture and Sports; Naberezhna Pobedy str., 10, Dnieper, 49010, Ukraine.

Bohuslavskyi V.V.; http://orcid/org/0000-0003-0806-0860; v_bogyslavckiy@icloud.com; Manager of Department of the Special Physical Preparation, Dnipropetrovsk State University of Internal Affairs; Gagarin boulevard, 26, Dnieper, 49005, Ukraine.

Ivchenco O. M.; http://orcid/org/0000-0003-2688-4505; basket.ivchenko@gmail.com; Manager of Department of the Special Physical Preparation, Dnipropetrovsk State University of Internal Affairs; Gagarin boulevard, 26, Dnieper, 49005, Ukraine.

Cite this article as:

Solovey OM, Mitova OO, Solovey DO, Boguslavskyi VV, Ivchenko OM. Analysis and generalization of competitive activity results of handball clubs in the game development aspect. Pedagogy of physical culture and sports, 2020;24(1):36-43. https://doi.org/10.15561/18189172.2020.0106

This is an Open Access article distributed under the terms of the Creative Commons Attribution License, which permits unrestricted use, distribution, and reproduction in any medium, provided the original work is properly cited (http://creativecommons.org/licenses/by/4.0/deed.en).

Received: 20.09.2019

Accepted: 25.10.2019; Published: 10.11 .2019 